DOI: 10.17516/1997-1397-2021-14-6-690-699

УДК 512.54

\title{
Modeling of Surface Fracture in Friction Interaction of Fiber Composites
}

\author{
Irina G. Goryacheva* \\ Almira R. Meshcheryakova ${ }^{\dagger}$ \\ Ishlinsky Institute for Problems in Mechanics of the Russian Academy of Sciences \\ Moscow, Russian Federation
}

Received 10.04.2021, received in revised form 10.06.2021, accepted 20.08.2021

\begin{abstract}
The model of the frictional interaction of a fiber composite material with a rigid nonwearing body is proposed, which makes it possible to study the effect of the mechanical and strength characteristics of the fiber and matrix materials and the composite structure on its stress state, in particular, at the fiber-matrix interface. Analysis of the stress distribution in the subsurface layers of the composite was carried out for different values of the ratio of matrix to fiber materials hardness, the sliding friction coefficient and the distance between the fibers. For the known failure criteria of fiber composites, the conclusions about the effect of the structure and relative strength properties of a fiber (fiber bundle) and matrix on the pattern of subsurface fracture of the composite under sliding friction conditions are made.
\end{abstract}

Keywords: frictional interaction, fiber composite, stress state, fracture.

Citation: I.G. Goryacheva, A.R. Meshcheryakova, Modeling of Surface Fracture in Friction Interaction of Fiber Composites, J. Sib. Fed. Univ. Math. Phys., 2021, 14(6), 690-699.

DOI: 10.17516/1997-1397-2021-14-6-690-699.

\section{Introduction}

The inhomogeneity of the structure of composites does not allow the use of the failure models of monolithic materials [1] for evaluation their strength, therefore, it is necessary to develop new models to describe the processes of their deformation and fracture. A review of various approaches for description of the mechanical behavior of composite materials is given in [2].

Fiber composites are a separate class of composite materials that consist of structural bundles of fibers or individual fibers and a matrix, and they differ in length, location of bundles or fibers and manufacturing method. The main mechanical characteristics of the fiber and matrix material are elastic modulus, strength at room temperature, strength and creep resistance at elevated temperatures [3].

To evaluate the strength of composite materials, criteria related to the limiting or reduced values of the stress tensor components and depending on the mechanism of fracture are applied [4], which use data from standard tests of specimens for uniaxial compression, tension, shear, etc In computational practice, the most common are the Tsai-Hill, Tsai-Wu and Hoffman quadratic

\footnotetext{
*goryache@ipmnet.ru https://orcid.org/0000-0002-4769-5482

$\dagger$ mif-almira@ipmnet.ru https://orcid.org/0000-0002-5938-5633

(C) Siberian Federal University. All rights reserved
} 
criteria [2], which are represented by polynomials containing stress or deformation tensor components. An overviews of the failure criteria for fiber composite materials are given in $[1,5,6]$. It is shown in [3] that the strength of the composite fiber material nonmonotonically depends on the volumetric content of the reinforcing fibers due to the coordinated failure of the contacting fibers. The strength of fiber composites is also influenced by the properties of the bonding layer between the fiber and the matrix, as indicated by the results of tensile testing of composites $[5,7]$.

Modeling of steady-state wear of fiber composites taking into account their structure (size and arrangement density of fibers, relative hardness of fiber and matrix material) was carried out in [8]. The results of the study show that the shape of the worn surface depends on the size and concentration of the composite fibers and the ratio of matrix to fiber materials hardness. The paper [9] is devoted to the experimental analysis of the influence of the direction of fibers with respect to the friction surface on the formation and the thickness of surface films (the third body) as a result of wear of the composite.

The purpose of this study is to model the frictional interaction of a fiber composite material with a rigid, wear-free body and to investigate the effect of the structure of the composite's surface layers on its stress state and the mechanism of subsurface fracture.

\section{Problem formulation}

We consider the sliding of an infinite rigid stamp with a flat base on an elastic structurally inhomogeneous half-space, which is a model of a fiber composite material consisting of a matrix and fibers (or bundles of fibers) with a circular cross-section of a constant radius, which are located perpendicular to the friction surface. We introduce the coordinate system Oxyz, the origin of which coincides with the center of the cross-section of an individual arbitrary fiber (or bundle of fibers) on the surface of the half-space, the direction of the axis $O x$ coincides with the sliding direction of the infinite rigid stamp, and the axis $O z$ is directed into the depth of the elastic half-space (Fig. 1). The surface region $\omega_{i j}$, corresponding to the cross-sections of a fiber (or a bundle of fibers) with index $i(j)$ along the axis $O x(O y)$ is a circle of radius $a$. The fiber cross-sections are located at the centers of the nodes of a square grid with a period $l$ in both directions.

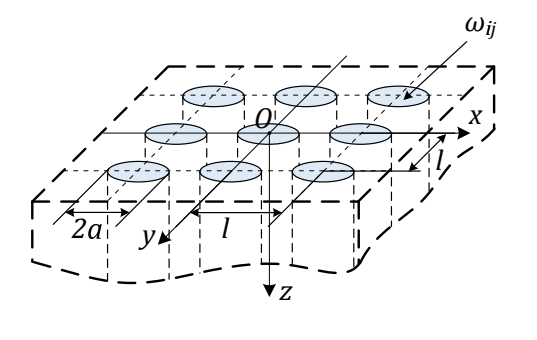

Fig. 1. The scheme of fibers (or fiber bundles) arrangement in a composite

When the punch slides in the direction of the axis $O x$ the Coulomb-Amonton law acts within the contact region, according to which the shear stresses $\vec{\tau}(x, y)$ and the contact pressure $p(x, y)$ 
are related as follows:

$$
\vec{\tau}(x, y)=-\mu p(x, y) \frac{\vec{V}}{|\vec{V}|},
$$

where $\mu$ is the sliding friction coefficient, $\vec{V}$ is the vector of the sliding velocity. As follows from (1), the shear stresses are directed opposite to the direction of the sliding velocity.

\section{The contact pressure distribution in steady-state wear}

For many types of wear, the wear equation as the dependence of rate of change of a point on the body's surface position in the direction perpendicular to its boundary, i.e. the linear wear of the surface $w(x, y, t)$, on the contact pressure $p(x, y)$ and sliding velocity $V=|\vec{V}|$ can be written in the following form [10,11]:

$$
\frac{d w(x, y, t)}{d t}=K_{w} p(x, y, t)^{\alpha} V^{\beta},
$$

where parameters $\alpha, \beta$ and the wear coefficient $K_{\omega}$ depend on the properties of materials, temperature and contact interaction conditions. Based on the results of experimental research [12], we assume that the wear coefficient $K_{w}$ for the considered structurally inhomogeneous material is a piecewise constant function, and the ratio of the fiber $K_{w}^{f}$ to matrix $K_{w}^{m}$ wear coefficients is inversely proportional to the ratio of the fiber $H_{f}$ to matrix $H_{m}$ materials hardness [11].

Let us consider a steady-state wear, for which the wear rate, determined by relation (2), is the same at all points of the surface $(x, y)$. Since the velocity $V$ of relative sliding for all points of the surface is also the same, then, as follows from (2), during the steady-state wear, the contact pressure distribution $p(x, y)$ over the surface of the composite material has the following form:

$$
p(x, y)= \begin{cases}p_{m}, & (x, y) \notin \omega=\bigcup_{i, j} \omega_{i j} \\ p_{f}, & (x, y) \in \omega\end{cases}
$$

where $p_{m}$ is the contact pressure value in the region of the matrix, $p_{f}$ is the value of the contact pressure in the region of the fiber (or bundle of fibers) and $\frac{p_{m}}{p_{f}}=\left(\frac{H_{m}}{H_{f}}\right)^{\frac{1}{\alpha}}$.

In the coordinate system $O x y z$ (Fig. 1) the composite's surface region $\omega_{i j}$, occupied by the fiber is given by the following expression:

$$
\omega_{i j}:\left(\frac{x-i l}{a}\right)^{2}+\left(\frac{y-j l}{a}\right)^{2} \leqslant 1,
$$

where $l$ is the distance between the centers of the fibers or the fiber bundles in the direction of the axis $O x(O y)$ (grid period), and $a$ is the fiber radius. Calculations of the contact pressure were carried out for a constant nominal pressure $p_{0}$, i.e. pressure per unit area of the composite. In this case, the equilibrium condition was taken into account:

$$
p_{0} n^{2} l^{2}=\iint_{(x, y) \notin \omega} p_{m} d x d y+\iint_{(x, y) \in \omega} p_{f} d x d y,
$$

where $n$ is the total sufficiently large number of the considered fibers, selected from consideration of the negligible difference in the absolute values of the pressures on the fiber (or matrix) with increasing value $n$. 
From (3) and equilibrium condition (5), we obtain a function that describes the dependence of the dimensionless contact pressure in the fiber region on the ratio of matrix to fiber materials hardness and the ratio of the fiber radius to the distance between the fibers:

$$
\frac{p_{f}}{p_{0}}=\frac{1}{\pi\left(\frac{a}{l}\right)^{2}+\left(\frac{H_{m}}{H_{f}}\right)^{\frac{1}{\alpha}}\left(1-\pi\left(\frac{a}{l}\right)^{2}\right)}
$$

Analysis of function (6) shows that for $H_{m} / H_{f}<1$ it decreases monotonically with increasing ratio $a / l(a / l \leqslant 0.5)$. Fig. 2 shows the graphs of this function (solid lines) plotted for different values of the ratio $H_{m} / H_{f}$. The values $H_{m} / H_{f}$ taken in the calculations correspond to the ratios of matrix to fiber materials hardness in carbon-carbon fiber composites used in aircraft brakes [13]. The dashed lines represent the dependences of the dimensionless pressure $p_{m} / p_{0}$, acting on the matrix on the parameter $a / l$ at the same values of the ratio of matrix to fiber materials hardness. In calculations, the parameter $\alpha$ in (6) was taken equal to 1 . The results show that the pressures on the matrix, as well as on the fiber, increase with growing distance between the fibers (for a given fiber radius), while the pressure difference between the fiber and the composite matrix also increases. With a decrease of the ratio of matrix to fiber materials hardness, the pressure drop across the fiber and the matrix also increases (while their arrangement density is constant).

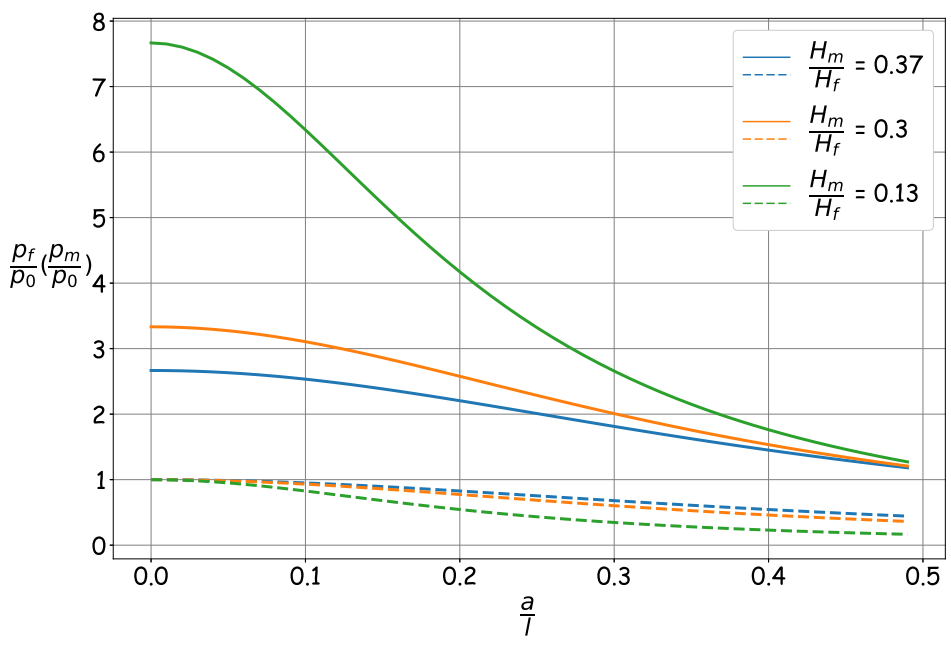

Fig. 2. Dependence of the contact pressure in the region of the fiber (solid lines) and the matrix (dashed lines) on the ratio of the radius of the fibers to the distance between them $a / l$ for different ratio of matrix to fiber materials hardness $H_{m} / H_{f}$

Note that during wear, the initially flat surface of the composite becomes wavy, which is confirmed by the results of many experiments [14]. In this case, the steady-state shape of the worn surface also depends on the composite's structure and the strength characteristics of its structural elements, and it can be calculated using the function (3) of the contact pressures distribution over the composite surface by the method described in [10]. 


\section{Calculation and analysis of the internal stresses in the composite's subsurface layers}

The stresses inside the composite material are determined by the mechanical characteristics of its structural elements and the distribution of normal and shear stresses at its boundary. For a number of fiber composites, in particular, carbon-carbon composites, the values of Young's moduli and Poisson's ratios of fiber and matrix materials are close to each other [13]. Therefore, in order to simplify the calculations of internal stresses in a composite material, we will consider it as a homogeneous elastic half-space, on the boundary of which there is a pressure described by a piecewise constant function (3) and shear stresses in accordance with formula (1).

To calculate the internal stresses at each point of the elastic half-space, we used the Boussinesq and Cerruti solutions for concentrated normal and tangential forces acting on the boundary of the half-space, and the superposition principle, which is valid within the framework of the linear theory of elasticity.

As shown in $[3,5,7]$ the failure of fiber composite materials primarily occurs along the interface between the fiber and the matrix. Therefore, to analyze the distribution of the stress tensor components inside an elastic half-space, we consider a cylindrical coordinate system, which axis $\mathrm{Oz}$ coincides with the symmetry axis of an arbitrary fiber, and the origin is located at the boundary of the half-space.

The influence of the dimensionless parameter $l / a$, characterizing the structure of the composite, the ratio of matrix to fiber materials hardness $H_{m} / H_{f}$, and the sliding friction coefficient $\mu$ on the distributions of the stress tensor components in the subsurface layers of the material was studied. The ratio of matrix to fiber materials hardness $H_{m} / H_{f}$ were selected on the basis of the known hardness of the structural elements of fiber-reinforced carbon-carbon composite materials, which were used in the analysis of contact stresses (Fig. 2), Poisson's ratio was taken equal to 0.3.

Figs. 3 and 4 show the isolines of the normal stress component $\sigma_{r} / p_{0}$ for different values of the dimensionless grid period $l / a$, in the half-space cross-section by a plane $y=0$ passing through the fiber symmetry axis and parallel to the punch velocity vector (Fig. 3), nand near the half-space surface for $z / a=0.01$ (Fig. 4).
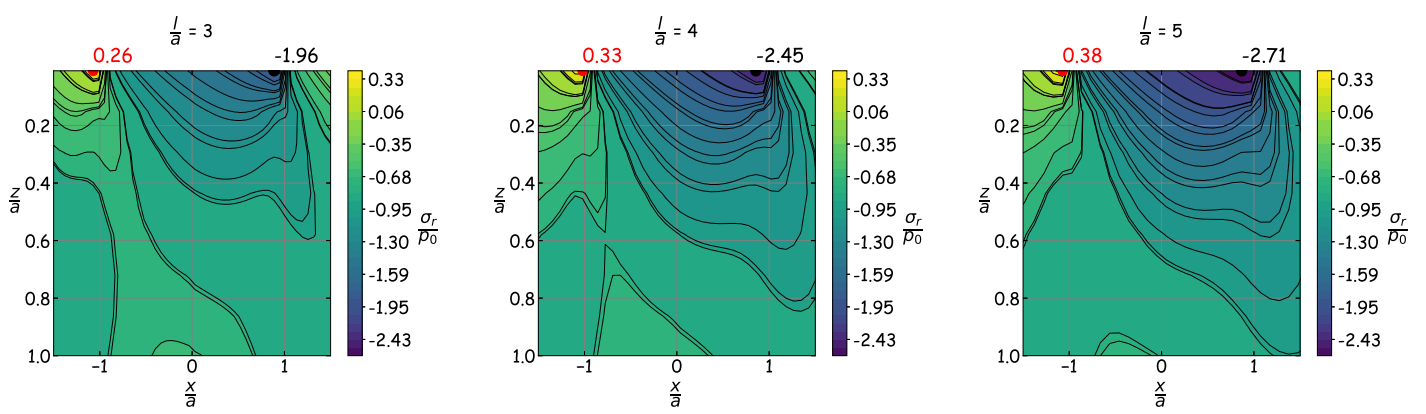

Fig. 3. The isolines of the stress component $\sigma_{r} / p_{0}$ in the half-space cross-section $y=0$ for $\mu=0.3$ and $l / a=3, l / a=4, l / a=5$

Negative values $\sigma_{r} / p_{0}$ ccorrespond to compressive stresses, and positive values - tensile stresses. Analysis of the calculation results allows us to conclude that the maximum values of tensile and compressive stresses are located on the surface of the half-space near the fibermatrix boundary; the compressive stresses appear on the front boundary of the fiber with respect 

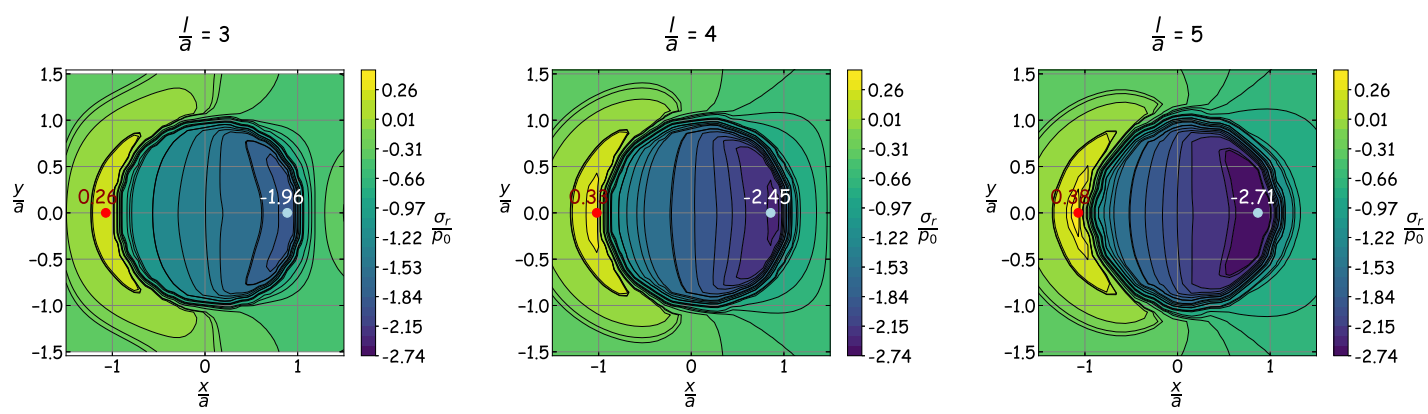

Fig. 4. The isolines of the stress component $\sigma_{r} / p_{0}$ near the surface of the half-space $(z / a=0.01)$ for $\mu=0.3$ and $l / a=3, l / a=4, l / a=5$

to the direction of motion, and the tensile stresses appear on the back. An increase of the distance between fibers leads to an increase of the absolute value of tensile and compressive stresses on the surface of the elastic half-space within the fiber.

The stress component $\sigma_{r} / p_{0}$ distributions near the surface of the half-space in the crosssection $y=0$ for different values of the dimensionless grid period $l / a$, sliding friction coefficient $\mu$ and the ratio of matrix to fiber materials hardness $H_{m} / H_{f}$ are presented in Fig. 5 .

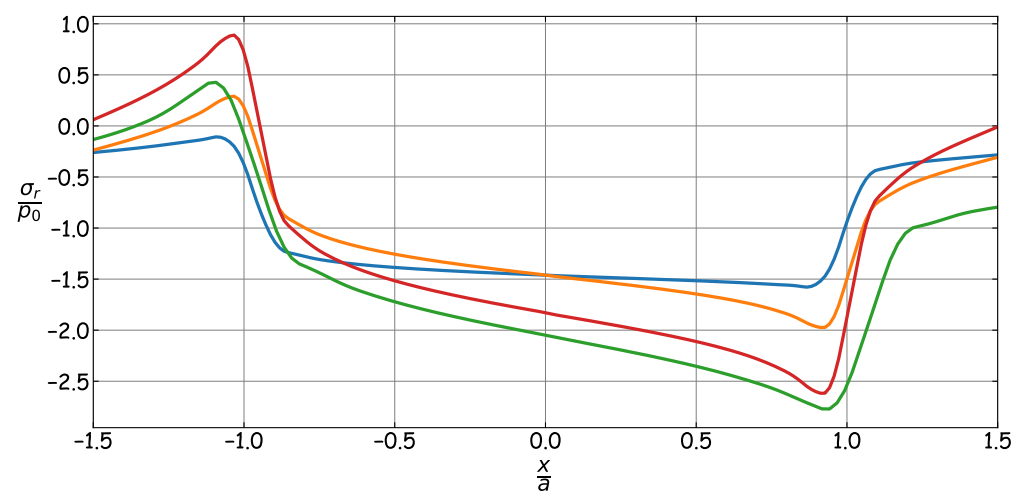

$$
\begin{aligned}
\square \frac{H_{m}}{H_{f}} & =0.3, \mu=0.1, \frac{l}{a}=3 \\
-\frac{H_{m}}{H_{f}} & =0.3, \mu=0.3, \frac{l}{a}=3 \\
-\frac{H_{m}}{H_{f}} & =0.3, \mu=0.3, \frac{l}{a}=5 \\
\frac{H_{m}}{H_{f}} & =0.13, \mu=0.3, \frac{1}{a}=3
\end{aligned}
$$

Fig. 5. The stress component $\sigma_{r} / p_{0}$ distribution near the surface $(z / a=0.01)$ in the crosssection $y=0$ for different values $H_{m} / H_{f}, \mu$ and $l / a$

As follows from the calculation results, the more the hardness of the fiber material differs from the hardness of the matrix, the greater the amplitude values between the highest tensile and compressive stresses at the fiber boundary in the cross-section $y=0$. For small value of the friction coefficient and close values of the hardness of the matrix and fiber materials, the stress component $\sigma_{r} / p_{0}$ near the entire boundary of the fiber is compressive. An increase of the sliding friction coefficient or a decrease of the ratio of matrix to fiber materials hardness lead to the appearance of a zone of tensile stresses and increase of the absolute values of compressive and tensile stresses $\sigma_{r} / p_{0}$, which are located near the interface between the fiber and the matrix.

Fig. 6 shows the isolines of the shear stress component $\tau_{r z} / p_{0}$ in the half-space cross-section by a plane $y=0$, passing through the fiber symmetry axis and parallel to the punch velocity vector, for different values of the dimensionless grid period $l / a$. 

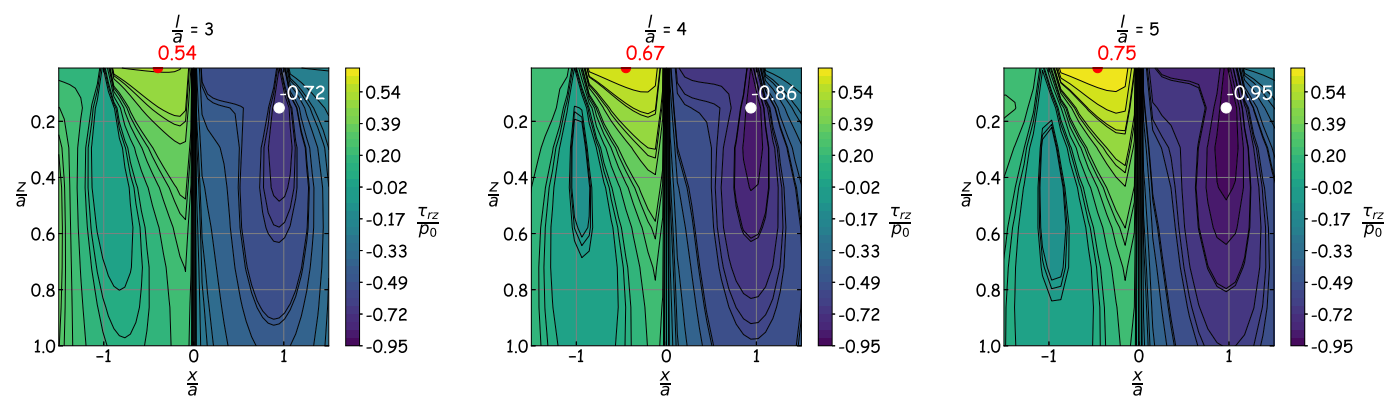

Fig. 6. The isolines of the stress component $\tau_{r z} / p_{0}$ in the half-space cross-section $y=0$ for $l / a=3, l / a=4, l / a=5$

The calculation results show that the highest absolute values of stresses $\tau_{r z} / p_{0}$ are located under the surface near the fiber-matrix interface. Fig. 7 illustrates the dependences of the shear stress component $\tau_{r z} / p_{0}$ in the cross-section $y=0$ of the half-space at the fiber-matrix interface (at $x / a=1$ ) on the dimensionless depth $z / a$ for different values of the sliding friction coefficient $\mu$, dimensionless distance between the fibers $l / a$ и and the ratio of matrix to fiber materials hardness $H_{m} / H_{f}$.

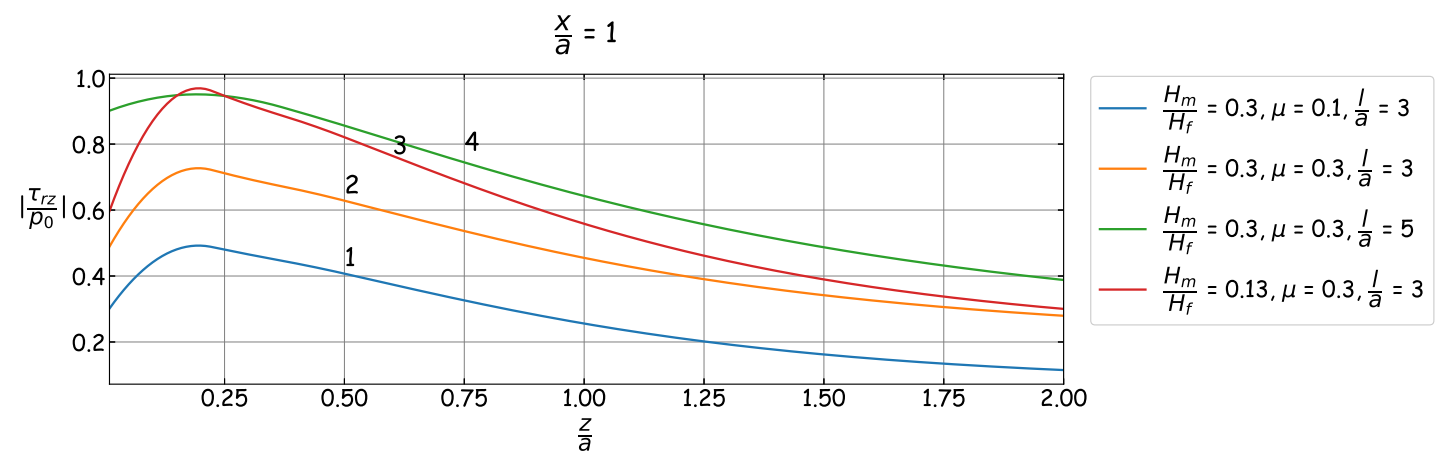

Fig. 7. Dependence of the absolute values of the stress component $\left|\tau_{r z} / p_{0}\right|$ on the distance to the surface $z / a$ in the half-space cross-section $y=0$ for $x / a=1$ and different values $H_{m} / H_{f}$, $\mu, l / a$

The results show that the shear component $\tau_{r z} / p_{0}$ of the stress tensor directed along the axis $O z$ varies nonmonotonically with depth, tending to zero at infinity. Its maximum values are reached at a depth of approximately 0.2 of the fiber radius, while the absolute values of stresses grow with an increase of the friction coefficient and with a decrease of the ratio of matrix to fiber materials hardness. With an increase of the distance between the fibers (curves 2 and 4), the absolute values of the shear stresses at a fixed depth increase.

The calculation of the stress tensor component $\tau_{r \theta} / p_{0}$ inside the half-space in the vicinity of the symmetry axis of an arbitrary fiber showed that the maximum values of the shear stresses in the circumferential direction are achieved at the interface between the fiber and the matrix on the composite surface. Fig. 8 illustrates the dependence of the stress component $\tau_{r \theta} / p_{0}$ in the cross-section $x=0$ of a half-space near the surface for different values of the sliding friction coefficient $\mu$, a dimensionless distance between the fibers $l / a$, and the ratio of matrix to fiber materials hardness $H_{m} / H_{f}$. Since the distribution $\tau_{r \theta} / p_{0}$ in the cross-section $x=0$ is symmetric 
with respect to the origin for the selected sliding direction, Fig. 8 shows the stress distribution for $y>0$.

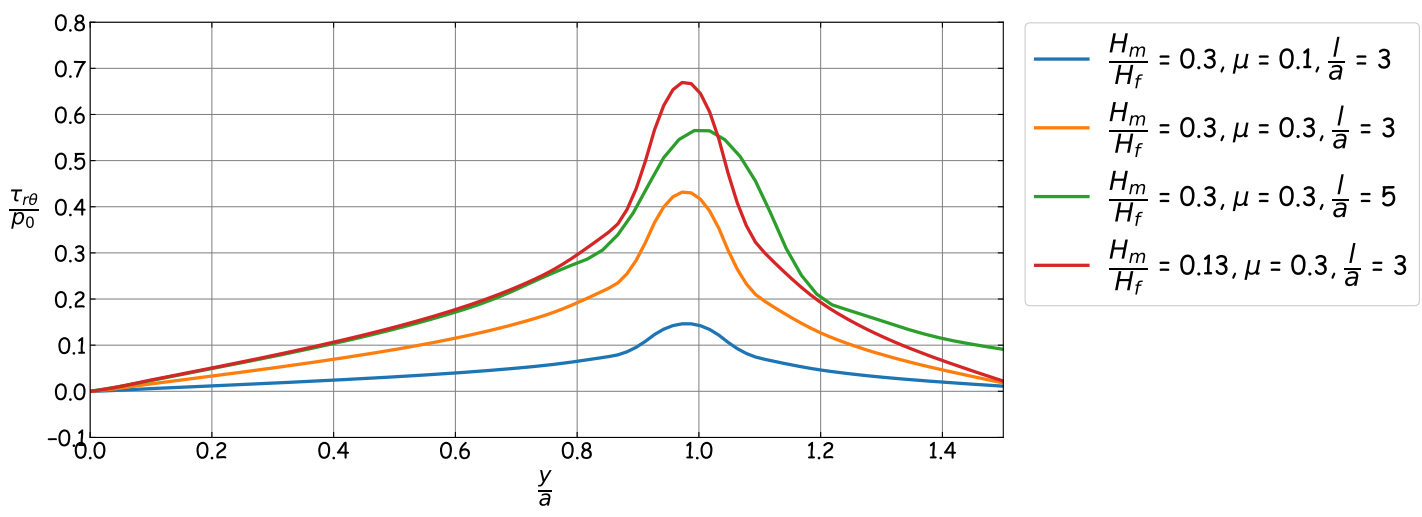

Fig. 8. Distribution of the stress component $\tau_{r \theta} / p_{0}$ near the surface of the half-space $(z / a=0.01)$ for different values $H_{m} / H_{f}, \mu$ and $l / a$

The calculation results allow us to conclude that the highest stress values $\tau_{r \theta} / p_{0}$ occurring at the interface between the fiber and the matrix grow with an increase of the friction coefficient and the distance between the fibers. In this case, the more the hardness values of the matrix material and the fiber differ, the greater the maximum absolute values of the function $\tau_{r \theta} / p_{0}$.

\section{Influence of the composite structure on its surface fracture in friction interaction}

To assess the pattern of fiber composite fracture under conditions of friction interaction, we use the failure criterion of unidirectional composite materials proposed in [5]:

$$
\psi\left(\sigma_{n}, \tau_{n}\right)=0,
$$

where $\sigma_{n}$ and $\tau_{n}$ are normal and shear stresses in the plane of possible failure.

For fiber composites, as noted in [5], fracture for the most part starts from the interface between the fiber and the matrix, which, as a rule, is less strong. The analysis of the normal and shear stresses at this boundary performed in the previous part allows us to draw some conclusions regarding the effect of the structural parameters of the composite (the ratio of matrix to fiber materials hardness, the density of the fiber bundles or the fibers themselves in the matrix), as well as the coefficient of friction and the kind of the relative displacements of bodies on the failure of the composite surface in conditions of frictional interaction.

As shown in Section 3, the components $\tau_{r \theta} / p_{0}$ and $\sigma_{r}$ of the stress tensor (in a cylindrical coordinate system) at the interface between the fiber and the matrix reach their maximum values on the friction surface, and the component $\tau_{r z} / p_{0}$ - below the surface at a depth of the order of $0.2 a$ ( $a$ is the radius of a fiber bundle or an individual fiber). Taking into account (7), it can be concluded that for composites containing bundles of fibers, the diameter of which is about $2-8 \mathrm{~mm}$, fracture is possible both at a certain depth below the surface and on the surface. For composites (or surface areas) containing individual thin fibers, fracture begins at the surface for any coefficient of friction. 
Since, as follows from (7), the fracture rate is influenced by the absolute values of stresses, it can be concluded that at given values of the nominal pressures, the fracture rate increases both with a significant difference in the hardness of the matrix and the fiber, and with an increase of the distance between the fibers.

A decrease of the friction coefficient reduces the value of stresses at the fiber-matrix interface, which, in turn, reduces both the probability of the fracture initiation and its rate.

The fact of the presence of both tensile and compressive stresses in the composite near the friction surface can cause the accumulation of fatigue damage in the composite's surface layers under conditions of cyclic reciprocating motion of the counterbody along it. The pattern of damage accumulation process and failure of the composite surface by the fatigue mechanism, as well as the thickness of the separated fragments, as follows from the studies carried out in Section 4, is largely influenced by the composite structure.

\section{Conclusions}

The influence of the composite structure, mechanical and strength characteristics of fiber and matrix materials on the distribution of contact pressures in the steady-state wear and the internal stresses within the composite, in particular, the stress distribution at the fiber-matrix interface, is analyzed. It is shown that the ratio of matrix to fiber materials hardness, the sliding friction coefficient and the distance between the fibers have the greatest influence on the stress distribution at the fiber-matrix interface. On the basis of the known strength criteria of fiber composites, conclusions are drawn regarding the pattern of failure of the fiber composites surface layers under conditions of friction interaction. The effect of the structure and relative strength properties of the fiber (fiber bundle) and matrix on this process is also discussed.

The research was supported by RSF (project no. 19-19-00548).

\section{References}

[1] E.I.Oreshko, V.S.Erasov, D.V.Grinevich, P.V.Shershak, Review of Criteria of Durability of Materials, Proceedings of VIAM, 81(2019), no. 9, 108-126 (in Russian).

[2] V.M.Sadovskii, O.V.Sadovskaya, I.E.Petrakov, On the theory of constitutive equations for composites with different resistance in compression and tension, Compos. Struct. Elsevier Ltd, 2021, 113921.

[3] S.T.Mileiko, Composites and Nanostructures, Composites and Nanostructures, (2009), no. 1, 6-37 (in Russian).

[4] A.S.Vasiliev, Mathematical modeling and numerical research of composite materials in the state of ultimate strength, PhD Thesis, Komsomolsk-on-Amur, 2016 (in Russian).

[5] A.N.Polilov, N.A.Tatus, Experimental Substantiation of Strength Criteria for FRP Showing Directional Type of Fracture, PNRPU Mechanics Bulletin, (2012), no. 2, 140-166 (in Russian).

[6] A.E.Burov, Models of Failure of Fibrous Composites, Bulletin of Reshetnev Siberian State University of Science and Technology, (2008), no. 3, 133-138 (in Russian). 
[7] V.B.Litvinov, L.P.Kobetz, M.S.Toksanbaev, I.S.Deev, L.M.Buchnev, Structural and Mechanical Properties of High-Strength Carbon Fibers, Composites and Nanostructures, 3(2011), 36-50 (in Russian).

[8] I.G.Goryacheva, Y.YMakhovskaya, Modeling of Fiber Composite Wear, Multiscale Solid Mechanics, ed. H. Altenbach, V.A. Eremeyev, L.A. Igumnov, Springer International Publishing, 141(2021), 163-174.

[9] T.J.Hutton, D.Johnson, B.McEnaney, Effects of fibre orientation on the tribology of a model carbon-carbon composite, Wear, 249(2001), no. 8, 647-655.

[10] I.G.Goryacheva, Contact Mechanics in Tribology, Kluwer Academic Publishers - Dordrecht, 1998.

[11] A.V.Chichinadze, M.Hebdy, Spravochnik po tribotekhnike (Handbook on Tribotechnique), Moscow, Mashinostroenie, 1989 (in Russian).

[12] I.V.Kragelsky, M.N.Dobychin, V.S.Kombalov, Friction and Wear: Calculation Methods, Oxford (UK), Pergamon, 1982.

[13] K.S.Kravchuk, Measurement of the tribological properties of coatings and composite materials at the submicron and nanometer scale, PhD Thesis, Moscow 2015 (in Russian).

[14] A.G.Shpenev et al., The study of the surface fracture during wear of C/C fiber composites by SPM and SEM, Procedia Struct. Integr. Elsevier B.V., 28(2020), no. 2019, 1702-1708.

\title{
Моделирование разрушения поверхностных слоев волокнистых композитов в условиях фрикционного взаимодействия
}

\author{
Ирина Г. Горячева \\ Альмира Р. Мещерякова \\ Институт проблем механики им. Ишлинского Российской академии наук \\ Москва, Российская Федерация
}

\begin{abstract}
Аннотация. Предложена модель фрикционного взаимодействия волокнистого композита с жестким неизнашиваемым телом, позволяющая исследовать влияние механических и прочностных характеристик материалов волокна и матрицы и структуры композита на его напряжённое состояние. Проведен анализ распределения напряжений на границе волокна и матрицы для разных значений отношения твердостей материалов матрицы и волокна, коэффициента трения скольжения и расстояния между волокнами. На основе известных критериев прочности волокнистых композитов сделаны выводы о влиянии структуры и относительных прочностных характеристик волокна (пучка волокон) и матрицы на характер подповерхностного разрушения композита в условиях трения скольжения.
\end{abstract}

Ключевые слова: фрикционное взаимодействие, волокнистый композит, напряженное состояние, разрушение. 